Research Article

Sukatiman*, M. Akhyar, Siswandari, and Roemintoyo

\title{
Enhancing Higher-Order Thinking Skills in Vocational Education through Scaffolding- Problem Based Learning
}

https://doi.org/10.1515/eng-2020-0070

Received Nov 06, 2019; accepted Mar 03, 2020

\begin{abstract}
Aim of the study is to implement Geomatics learning innovations by applying the scaffolding ProblemBased Learning integrated model to improve the student's Vocational HOTS. The method applied was qualitative with the participation of 2 groups of students practicing consisting of 4 people each. The level of cognitive mastery was measured with the Bloom taxonomy (C1-C6). The results of the investigation showed that the integrated model effectively formed students' Vocational HOT Skill as a group in 3 stages. The first stage of learning focused on mastering the operation of equipment needed in practice (C2-C3 and partly C4). In the second stage, the students have mastered most of the cognitive analysis and accuracy of practical data (C4-C5) and in the third stage, they made practiced steps more effectively and successfully correlated to the Indonesian National Standards (SNI) level (C6) at the moderately accurate. The application of the Scaffolding ProblemBased Learning model has a positive impact that students get21st-century learning with the main characteristics (4C), consisting: Communication, Collaboration, (Critical thinking, and problem-solving), and Creative thinking. Learning outcomes enriched with higher-order thinking skills can be seen when students take advanced Geomatics material, They already work with groups to map the area more independently
\end{abstract}

Keywords: Scaffolding, Problem-based learning integrated model - ICT based- Higher ordered thinking skills in vocational

\footnotetext{
^Corresponding Author: Sukatiman: Doctorale program, Faculty of Teacher Training and Education, Universitas Sebelas Maret, Indonesia

M. Akhyar: Doctorale program, Faculty of Teacher Training and Education, Universitas Sebelas Maret, Indonesia

Siswandari: Doctorale program, Faculty of Teacher Training and Education, Universitas Sebelas Maret, Indonesia

Roemintoyo: Doctorale program, Faculty of Teacher Training and Education, Universitas Sebelas Maret, Indonesia
}

\section{Introduction}

The Indonesian regulation minister of education and culture No.103, 2014) [1] about the Implementation of the 2013 Curriculum, which was later revised in 2018, states that there are several new things that become the differentiate with the Lesson Plan (RPP-K13), one of which is integrating HOTS (Higher-Order Thinking Skill) or Bloom's Taxonomy Level 3 (C4 to C6) [2].

Higher-order thinking skill is still very crucial for high schools and vocational schools. it is proofed by the result of the 2018 national exam shows that 40 percent of students still have difficulty solving questions based on higher-order thinking skills [3]. The problem proof of the HOTS of high school and vocational high school graduates, when a pretest was given to the new civil engineering education (PTB) students. The questions in the form of essays related to the basics of Geomatics. The topic given is analyzing the angles of the triangle, calculation of the sides of the triangle, and the area of the triangle both the perpendicular angles and not-perpendicular angles with different levels of difficulty. The results of the students analyzed showed they can complete calculations for easy questions (level C1-C2) 92.6 percent of the pretest, medium questions (C3-C4) 74 percent completed, and difficult questions (level C5-C6) 0 (zero) percent. To break the chain of high school/vocational graduates who are not yet skilled in HOTS, then in higher education the learning process should be carried out with HOT-based learning.

\subsection{Why HOT?}

HOTS learning will prepare students for success in the challenging workforce today [4]. Other researchers state that the HOTS learning model is the answer to complex questions and solutions of a case or problem through real learning [5]. Define HOTS is the ability to think critically, logically, reflectively, using metacognitive, and creative thinking which are the abilities to think at a higher level.

¿ Open Access. (c) 2020 Sukatiman et al., published by De Gruyter. (Cc) BY 4.0 License 
Newman [6] states LOT (Lower-Order Thinking) is a routine application such as ordering a list of information, remembering, and applying the existing formulas. Meanwhile, HOT presents a challenge for students to interpret, analyze, or manipulate information.

\subsection{How to shape HOTS in vocational education?}

HOT formation in learning, especially in the field of vocational education, is carried out by applying practical learning. Kultusminister Konferenz [7] reinforces that the purpose of vocational education and training requires that students' learning be focused on tasks that have an action orientation and students be given the opportunity independently to plan, carry out and assess work assignments in the context of their professional activities. This is in line with the opinion of Web and Moallem [8] that students in small groups work together to analyze, formulate, and then work together to solve problems.

\subsection{What is the significance of scaffolding in the problem-solving process?}

Bruner [9] states that assistance or scaffolding has visible characteristics, namely 1) task simplification, 2) giving instructions to students in achieving goals, 3) controlling despair during problem-solving, and 4) demonstrating and describing ideally the activities to be carried out. The study of Palesy [10] found that scaffolding is needed in the workplace where individuals work without direct supervision, but are more dependent on small groups and learn through hands-on practice with the help of skilled colleagues and written materials (handouts and work procedures) as supporting materials. This type of scaffolding learning is very suitable for practical learning and the function of the instructor is as a motivator, facilitator and guide at the beginning (scaffolding). Besides, the development of theory and instructional activities of the teacher is still needed in learning.

Problem-based learning is used in this teaching as the main machine scheme which aims to construct its learners independently. Instructional lectures are given in educational classrooms that will provide fuel for PBL, so a balance is needed when the learning scheme includes several types of teaching methods [11].

\subsection{ICT Utilization in Learning}

The main disadvantage of the face-to-face conventional learning model is the limited face-to-face time in class with huge materials and tasks so that learning becomes less absorbed if students cannot use ICT. Thus, ICT facilities, especially online materials, are one of the facilities for students. This tendency influences not only the goals, content and learning process but also the design and development of approaches in studies and professional practice.

Distance learning (e-learning) can enhance and precipitate knowledge and promote broad access to increase student participation [12]. In this study, ICT assistance is very useful in providing mastery of the material to students. The researcher choose the Edmodo application because the program has many advantages in learning, including giving students bond, participation, and discussion with friends including communicative learning and the student's social development [13]. Edmodo application program can be accessed by students through mobile phone gadgets which are certainly owned by this millennial generation. Evaluation of student learning outcomes is a challenge while using ICT equipment because teachers not only assess the students' knowledge mastery but also develop their critical-thinking and problem-solving skills [14]. The opinions of experts/researchers about the use of ICT in learning above can provide an overview of the importance of ICT to support the students' learning process and outcomes in critical and high-order thinking.

The model in question is the integration of Scaffolding and problem-based learning with ICT support. Thus, this study aims to improve learning outcomes in the Geomatics course with the integrated learning concept: 1) scaffolding, 2) problem-based learning (PBL) with ICT support, and 3) evaluating students' practices with HOT characteristics. The vocational learning model that has the uniqueness as explained above, I call it the term Vocational HOTS (V-HOTS).

\subsection{Syntax Learning to Develop V-HOTS}

From the results of the published literature study presented above, the researcher developed an integrative model of the scaffolding and problem-based learning (ScffPBL) by strengthening ICT in supporting the students' motivation to actively learn. The learning syntaxes are as follows:

1. Determining learning objectives

2. Providing the real problem of the mapping process in the field. 
3. Providing supporting theory materials for practice by introducing the Geomatics field with examples uploaded as an e-learning material using Edmodo application that can be accessed through mobile phones.

4. Providing learning reinforcement through multimedia e-learning about measurement instructions with semi-digital device (Sokkia DT-6). This multimedia is in the form of a learning video.

5. Guiding and procedural practice by utilizing ICT (manual and semi-digital theodolite equipment) to provide a basis for students' initial competencies. Note: detailed guidance is given for the operation of the tool and the determination of the initial coordinate point (Bench Marked $=\mathrm{BM}$ ), and students change roles in teamwork. Conversely, for material deepening, the student is only given guidance when needed.

6. Guiding on how to draw field sketches that will be used as objects of student practice, which aims to be reconstructed into more detailed steps to obtain measurement data.

7. Explaining the practice evaluation system including a minimum graduation standard of 80 .

8. Dividing 2 existing classes into smaller groups (8 groups).

9. Reminding about initial competencies that the students have mastered (scaffolding), namely the leveling theory and determining angles and distances with optical-based devices (leveling tools and theodolites).

10. Then, they identify existing problems.

11. Students make the methods and implementation needed by following the conditions in the field and calculate the needs of field data.

12. Comparing the results of student measurements with the applicable standards in Indonesia SNI [15, 16].

13. Presenting practice results.

14. Documenting the practice results through portfolio reports.

\section{Research Methodology}

Ethnography is research conducted to observe, interview, study in the real field about social life and dialogue because the conclusions and interpretations made through it can be given comments or feedback from what they do [17]. The characteristics of an ethnographic study, among oth- ers, are the study with small cases, unconstructed data (inductive) that focuses more on the findings in the field than data interpretation. The method used in conducting the evaluation is the equivalent test, which is a test to measure its reliability identically with the reference test. Each appearance, except the substance of the item, can be different. The evaluation has the same character. The characteristics in question include measuring the same variable, having the same number of items, having the same structure, and having levels of difficulty and the same instructions, scoring method, and interpretation.

The investigation was conducted in 2 groups of students who were following the practice of basics of land surveying/Geomatics in the Construction Education Study Program, Faculty of Teacher Training and Education of Universitas Sebelas Maret (PTB-FKIP UNS). To get the first feature of forming V-HOT skills, the students were divided into small groups of 4 students. By minimizing group members, each student has a more tangible role in practice. This small group was given the case study task as follows: 1) measuring the angles of several targets it with the optical method and comparing with manual measurements, 2) measuring cut and fill with the net method, and 3) Making bow plank (staking out) in the field. These topics were complemented with case studies (Problem Based Learning). On topic 1 , the case study was given in the form of a mild case targeting a particular object; On topic 2, a medium case study was given on an contour land; On topic 3 , the case study provided by the researcher was a severe case of unstructured a case study. To make it easier to collect the data, coding was done on the data source. For practical students, they were given S1-S4 codes according to the number of students in the group. Codes A1 to A4 show 4 student assistants, codes I1 and I2 are for the instructors of the day's practice, and code $\mathrm{Tl}$ is for laboratory tool. For coding, the practice groups were divided into two, namely WTG (Wild T0 group) and TG (Topcon group).

Another characteristic in obtaining the Geomatics material HOT is that the practice of measuring the land surveying is ICT based (using technological equipment (theodolite) by applying a global reference point (Global Position System = GPS) and supported by the online application program (Edmodo). Another feature to get V-HOT in this study was by conducting a HOT-based evaluation which includes: 1) evaluation by observation process, 2) online objective test with the Edmodo application program that can be done on student mobile phones, and 3) test of theodolite tool operation. The data from some of the evaluations were used as data triangulation to conclude the improvement of the students' V-HOTs. The researcher also set a 
Table 1: Evaluation Outline of Process to Acquire V-HOT Skills

\begin{tabular}{|c|c|c|c|c|c|}
\hline No & Item Measured & $\begin{array}{l}\text { Cognitive } \\
\text { level }\end{array}$ & Quality & $\begin{array}{c}\text { Achievement } \\
\text { Score }\end{array}$ & $\begin{array}{l}\text { Quality } \times \\
\text { achievement } \\
\text { Score }\end{array}$ \\
\hline 1 & Estimating the need for tools to be used & $\mathrm{C2}$ & 5 & & \\
\hline 2 & Adjusting Stative tuning, equipment and nivo & C3 & 7 & & \\
\hline 3 & Mentioning parts and functions of the tool & $\mathrm{C3}$ & 7 & & \\
\hline 4 & Adjusting $\mathrm{V}$ and $\mathrm{H}$ from the tool & $\mathrm{C} 4$ & 10 & & \\
\hline 5 & Analyzing the need of data & $\mathrm{C} 4$ & 10 & & \\
\hline 6 & Analyzing the accuracy of the target shooting data & $\mathrm{C} 4$ & 10 & & \\
\hline 7 & $\begin{array}{l}\text { Analyzing the accuracy of the target shooting data and the } \\
\text { tool height }\end{array}$ & $\mathrm{C} 5$ & 12 & & \\
\hline 8 & Creating to efectiveness & C6 & 15 & & \\
\hline 9 & Communicating the data with SNI standards and reflecting & C5 & 12 & Inform & ation: \\
\hline 10 & Securing the data for continued use & C3 & 7 & LOT $(\mathrm{C} 2-\mathrm{C}$ & 3) $=31 \%$ \\
\hline \multirow[t]{2}{*}{11} & Ensuring the clarity of field sketch pictures & $\mathrm{C} 2$ & 5 & HOT (C4-C & 6) $=69 \%$ \\
\hline & total & & 100 & & \\
\hline
\end{tabular}

The full question and answer outline are documented by the researcher. Remark:
$\mathrm{C} 1=$ Remembering
$\mathrm{C} 3$ = Applying
C5 = Evaluating
$\mathrm{C} 2$ = Understanding
$\mathrm{C} 4=$ Analyzing
C6 = Creating

Group Scoring Achievement $=\frac{2(C 2 \times 5)+3(C 3 \times 7)+3(C 4 \times 10)+2(C 5 \times 12)+(C 6 \times 15)}{100}$

completeness standard of students of 75 (scale 0-100) and the percentage of students who passed was 80 percent.

The evaluation has the following conditions: 1) Students have been given guidance on the use of manual theodolite (Wild T0, Topcon, Shokisa, and Sokkia), 2) Students have understood the Basic Geomatics Module and the advanced Survey and Mapping module that have been uploaded on Edmodo application.Position System = GPS) and supported by the online application program (Edmodo).

Another feature to get V-HOT in this study was by conducting a HOT-based evaluation which includes: 1) evaluation by observation process, 2) online objective test with the Edmodo application program that can be done on student mobile phones, and 3) test of theodolite tool operation.

The provisions in working on the tasks: 1) The research group (8-10 students) was divided into 2 small groups (4-5 students); 2) The students might choose one of the theodolite equipment that has been taught; and 3) The teacher paid attention to differences in student characteristics (there were members who have a vocational school background and have studied Survey and Mapping), the gender balance of men and women, and the level of initial intelligence of students.
At the beginning of the lesson, the instructor provided assessment guidelines with the items like in Table 1 . These items show the steps to be applied by the practice group, from LOT items (C2-C3) to items that ensure the formation of students' V-HOT skills (C4-C6). The assessment weighting also considers the severity of the students' thinking, for LOT items, the quality is smaller than HOT items.

After learning preparation is done, then the learning process is implemented with the concept of learning-based Scaffolding by strengthening ICT, and continued with data collection. The data obtained were then analyzed descriptively quantitatively for all items collected in forming VHOTS.

\section{Results}

The process of forming students' V-HOT skills can be described as follows:

The first stage evaluation (Table 2) was performed after the students got the theory and practice of using theodolite (week-5th). The topic covered was measuring the shooting angle of several targets with a theodolite both regular and extraordinary measurements (bb-lb). The students were trained to be familiar with operating the tools, and at 
Table 2: Cognitive results to get HOTS in the first stagev

\begin{tabular}{|c|c|c|c|c|c|c|c|c|}
\hline \multirow[b]{2}{*}{ Hot Level } & \multirow[b]{2}{*}{ No } & \multirow[b]{2}{*}{ Items Measured } & \multirow[b]{2}{*}{$\begin{array}{l}\text { LOT } \\
\text { Level }\end{array}$} & \multirow[b]{2}{*}{ Quality } & \multicolumn{2}{|c|}{ WTG } & \multicolumn{2}{|l|}{ TG } \\
\hline & & & & & $\begin{array}{l}\text { Achievement } \\
\text { Score }\end{array}$ & $\begin{array}{c}\text { Quality } \times \\
\text { Achievement } \\
\text { Score }\end{array}$ & $\begin{array}{c}\text { Achievement } \\
\text { Score }\end{array}$ & $\begin{array}{l}\text { Quality } \\
\times \\
\text { Score }\end{array}$ \\
\hline \multirow[t]{7}{*}{ Scaffolding } & 1 & $\begin{array}{l}\text { Estimating the need } \\
\text { for the mapping tool } \\
\text { to be used }\end{array}$ & $\mathrm{C} 2$ & 5 & 80 & 400 & 70 & 350 \\
\hline & 2 & $\begin{array}{l}\text { Adjusting the posi- } \\
\text { tion of the device in } \\
\text { the field }\end{array}$ & C3 & 7 & 80 & 560 & 65 & 455 \\
\hline & 3 & $\begin{array}{l}\text { Stative tuning and } \\
\text { nivo }\end{array}$ & $\mathrm{C} 3$ & 7 & 80 & 560 & 75 & 525 \\
\hline & 9 & $\begin{array}{l}\text { Securing the data for } \\
\text { continued use }\end{array}$ & C3 & 7 & 70 & 490 & 65 & 455 \\
\hline & 10 & $\begin{array}{l}\text { Ensuring the clarity } \\
\text { of field sketch pic- } \\
\text { tures }\end{array}$ & $\mathrm{C} 2$ & 5 & 70 & 350 & 70 & 350 \\
\hline & & & & 31 & & 60 & 2135 & \\
\hline & & Scores $=$ & & & $2360 / 31=$ & & $2135 / 31=$ & \\
\hline
\end{tabular}

Explanation

WTG = Wild T0 Group. The students practice group used the theodholite Wild T0

$\mathrm{TG}=$ Topcon Group. The students practice used the theodholite Topcon

the level of problem-solving, they constructed their knowledge to identify differences in results that occurred between theory and practice. The observation results show the score of cognitive mastery of C2-C3 (item no 1, 2, 3, 9, 10) of Wild TO (WTG) group is 76 and Topcon group is (TG) 69.

These results indicate that: 1) the mastery of equipment operation from both student practice teams is still low. The cognitive skills (C2-C3) have not been fulfilled as indicated by, 1) the results of optical distance shots with theodolite devices and checking with roller meters that still missed more than $10 \mathrm{~cm}$ (not yet included in the accuracy standard [16], 2) the measurement of ordinary and extraordinary angles that is still far more than 10 (not yet included in the SNI accuracy standard). All of this evidence shows the tool set is still procedural and does not display the accuracy, and creativity of students.

From the first stage observations, it was also found that the WTG group students had mastered the operation of the tool (items 1,2,3 had reached a score above the standard set), but the TG group still needed intensive guidance/ full scaffolding from the assistant and and instructor so the use of tools can be mastered well (scores of items 1, 2,3 had not met the standard). No.9 and no.10 from the two groups have not yet met the standard set. From the results of the first stage of observation, it can be evaluated that the WTG group needs improvement in items no. 9 and 10 while the TG group still needs overall guidance.

In the second investigation carried out in week-8th with the topic of calculating the volume of cut and fill in the river cross-section. The topic of the problem raised by the researcher was a well-structured problem. The students were given a variety of guidance in solving the problem of analyzing the volume of cut and fill with a broadfaceted method.

In the observation of the Wild T0 group (WTG=see coding), the use of tools has been well mastered, as seen in items of using tools (no. 1-3) that have passed (Table 2). The investigation proves that this WTG group has better practice data (including SNI standards) and faster tool operation time than the TG practice group that used the Topcon theodolite.

For the Topcon (TG) group, the use of tools has not been fully mastered by the students, which can be seen from the items of use of tools (no. 1-3) in Table 2 that they have not met the standard set. Even in this group, the members still have to ask for guidance from other groups for operational equipment. This is justified by the instructor's 
Table 3: Cognitive evaluation result to get HOTS in the second stage

\begin{tabular}{|c|c|c|c|c|c|c|c|c|}
\hline \multirow{2}{*}{$\begin{array}{l}\text { HOT } \\
\text { Level }\end{array}$} & \multirow[b]{2}{*}{ No. } & \multirow[b]{2}{*}{ Items Measured } & \multirow[b]{2}{*}{$\begin{array}{l}\text { HOT } \\
\text { Level }\end{array}$} & \multirow[b]{2}{*}{ Quality } & \multicolumn{2}{|c|}{ WTG } & \multicolumn{2}{|l|}{ TG } \\
\hline & & & & & $\begin{array}{l}\text { Achievement } \\
\text { Score }\end{array}$ & $\begin{array}{l}\text { Quality } \\
\times \text { Score }\end{array}$ & $\begin{array}{l}\text { Achievement } \\
\text { Score }\end{array}$ & $\begin{array}{l}\text { Quality } \\
\times \text { Score }\end{array}$ \\
\hline Critical & 5 & Analyzing the need of data & $\mathrm{C} 4$ & 10 & 85 & 850 & 86 & 860 \\
\hline $\begin{array}{l}\text { Thinking } \\
(\mathrm{C} 4+\mathrm{C} 5)\end{array}$ & 6 & Calculation the data & $\mathrm{C} 4$ & 10 & 90 & 900 & 93 & 930 \\
\hline \multirow[t]{4}{*}{$\begin{array}{l}\text { Creativity } \\
\text { (C6) }\end{array}$} & 7 & $\begin{array}{l}\text { Analyzing the accuracy of tar- } \\
\text { get shooting data }\end{array}$ & $\mathrm{C5}$ & 12 & 75 & 900 & 73 & 876 \\
\hline & 8 & $\begin{array}{l}\text { Communicating the data with } \\
\text { SNI standard }\end{array}$ & $\mathrm{C} 6$ & 15 & 78 & 1170 & 75 & 1125 \\
\hline & & & \multicolumn{3}{|c|}{47} & \multicolumn{2}{|c|}{3820} & 5652 \\
\hline & & Score $=$ & & \multicolumn{2}{|c|}{$3820 / 47=81.28$} & \multicolumn{2}{|c|}{$3791 / 47=80.66$} & \\
\hline
\end{tabular}

data source (I-2) which asks group members to study with one of their peers (s7-TG) who can already operate the Topcon tool. The researcher realizes that peer learning (cohort) is more convenient for the practitioner to do than asking the assistant or instructor. Therefore, peer discussions outside the group were also allowed. After the group had mastered the use of the tools, they consulted for solving the problems encountered.

Overall, for LOT formation items on C2-C3 cognitive, the practice group does not have a good ability on item number 10 and 11, namely: 10 . Securing data for continued use and, 11. Ensuring the clarity of the field sketch pictures, so that the lecturer needs to guide on how to document measurement results by making clearer measurement formats accompanied by sketches of pictures that are easier to understand.

In this second stage, the researcher again collected the data through observation of the teaching and learning process of practical students. The results show that the operation of the equipment has been acquired by the practice group (included in SNI standards).It can be seen from Table 3 that the mastery of LOT has reached the target of the study, but the formation of HOT (no.5-8) still needs more guidance. In the formation of HOTS, the initial stage shows that the students have mastered HOTs for the items of calculating the data and analyzing the accuracy of target shooting data and the height of the tool. However, other HOT items are still low. Then, the lecturer provided guide on how to solve mapping problems. In the process of acquiring HOTS, students must learn to master HOTS (C4-C6) done in teamwork. The observations indicate that C4-C6 cognitive abilities have been already quite high but have not yet reached the standards set by the researcher.

In the third evaluation stage (Table 4), the C2-C3 domains have not been raised, and the evaluation is only aimed at the students' HOTS that has not been reached. The practice topic is setting up the bow plank in the field. The observations indicate that cognitive skills that have not yet been achieved are critical thinking and creativity. By giving relevant stimuli, the students found the creativity on the topic of bouwplank/ staking out measurements, where the Topcon practice group (TG) can make the measurement tool stand smaller than usual. Likewise, the Wild TO (WTG) group can pass coordinate calculations at points that cannot be occupied by the tool. From the HOTS achievement of the practice group in the field, there is no doubt that the instructor has given the score of HOTS (C4C6) that meet the standard.

The cognitive evaluation above is to evaluate the groups HOT. The formation of individual HOT was an evaluation by adding an activeness assessment that contributes positively to the group (not discussed). On the vice versa, penalties were also given to students who inhibit group assignments (not discussed). For the triangulation of data, the check the cognition of the students' HOT, the researcher provided an e-learning-based evaluation in the Edmodo application. The type of question is multiple choice totaling 20 items. The cognitive evaluation results from the investigation group showed that 7 students could answer correctly the questions given through Edmodo of more than 80 percent, one student got a 79 percent result, and one of the students selected in the action test (m4) got 100 percent. This shows that the students' HOT can achieve the score as the standard set by the researcher. 
Table 4: Cognitive evaluation results to Get HOTS in the third stage

\begin{tabular}{|c|c|c|c|c|c|c|c|c|}
\hline \multirow[b]{2}{*}{$\begin{array}{l}\text { НОT } \\
\text { Formation }\end{array}$} & \multirow[b]{2}{*}{ No } & \multirow[b]{2}{*}{ Items Measured } & \multirow[b]{2}{*}{$\begin{array}{l}\text { HOT } \\
\text { Level }\end{array}$} & \multirow[b]{2}{*}{ Quality } & \multicolumn{2}{|c|}{ WTG } & \multicolumn{2}{|c|}{ TG } \\
\hline & & & & & $\begin{array}{c}\text { Achievement } \\
\text { Score }\end{array}$ & $\begin{array}{c}\text { Quality } \times \\
\text { Achievement } \\
\text { Score }\end{array}$ & $\begin{array}{c}\text { Achievement } \\
\text { Score }\end{array}$ & $\begin{array}{c}\text { Quality } \times \\
\text { Achievement } \\
\text { Score }\end{array}$ \\
\hline \multirow[t]{4}{*}{$\begin{array}{l}\text { Creativity } \\
\text { (C6) }\end{array}$} & 7 & $\begin{array}{l}\text { Analyzing the ac- } \\
\text { curacy of target } \\
\text { shooting data }\end{array}$ & $\mathrm{C} 5$ & 12 & 87 & 1044 & 80 & 960 \\
\hline & 8 & $\begin{array}{l}\text { Communicating } \\
\text { the data with SNI } \\
\text { standard }\end{array}$ & C6 & 15 & 80 & 1200 & 85 & 1275 \\
\hline & & & & 27 & & 2244 & & 2235 \\
\hline & & score $=$ & & & & $2244 / 27=83.11$ & & $\begin{array}{c}2940 / 27= \\
82.78\end{array}$ \\
\hline
\end{tabular}

\section{Discussion}

The learning process contains theories that have been uploaded on the Edmodo application. The findings at the theoretical session show that students tend to be more active and motivated because they already have a basic knowledge of the topics discussed by reading on the Edmodo application. The emergence of this motivation is in accordance with the research of Hopson, Simms, and Knezek [18] who found that the creation of a technology-enriched classroom environment (ICT) had a positive effect on the acquisition of high-level thinking skills (HOTS) students.

In the practice session, the topic discussed was material measurement in the field using simple equipment, and the topic discussed was evaluating flooding on campus grounds, by calculating the difference in the height of the channel and the horizontal distance. The student's task is the practice of determining the height difference and calculating the run-off capacity that runs through the channel. The provision of tangible material in the field for vocational students is in line with the objectives of vocational learning where the aim of vocational training requires that lessons be taught pedagogically oriented, emphasizing action orientation and to independently plan, carry out, and assess tasks in a work context.The topic discussed was material Thematic courses are needed to solve the flood discharge evaluation problems, namely the Hydraulics and Water Building courses as a discussion. The appropriate topic is about open drainage planning. Problem-solving by integrating material in this thematic form is a following theory of Barrows [19], which states that to ensure the success of learning, all disciplines integrally (thematic) that support practice, need to be included in the PBL learning curriculum.

The results of the observation of the problem in the first stage showed that students still did not succeed in getting HOTS items. at this stage, students are not accustomed to solving problems integratively, so that achievement successfully completed is only limited at procedural items to operate the tools, and steps to obtain field data. To develop students' abilities in solving the problems, instructors and student assistants must concentrate on guiding practice groups, so that students can use the experience already mastered in analyzing the runoff or capacity of the channel. This is in accordance with Vygotsky [20], about Zone Proxima Development, where students need others to be able to develop their knowledge.

The observations in the second stage, the topic discussed was to calculate cut and fill. The discussion on this topic is to look at each height difference in a rectangular net so that the height of the vertex points of the grid shape can be understood. This learning includes thematic learning relating to cut and fill related to building construction materials, and road construction materials. In this study, the PBL used is a well-structured type. The main reason for using a type of well structured is because the main learning goal is theodolite training so that in the learning process the scaffolding / mentoring is preferred by both the instructor and student assistants. The results of the 3rd stage showed that the experimental group was able to construct knowledge in the field independently. The results of this study are by following the problem-based learning approach which prioritizes the process of problem-solving rather than the final result. 


\section{Conclusion}

The formation of V-HOTS in learning Geomatics practice can be carried out by integrating Scaffolding-Problem Based-Learning model (Scff-PBL). The model has been successfully carried out in 3 stages of the learning process, with reinforcement of V-HOT based assumptions given at the end of each of 3 stages. The first stage focuses more on guiding/ scaffolding (LOT $=39$ percent). The second stage focuses on the formation of V-HOT between scaffolding and PBL level analyses (C3). The third stage of learning focuses on how to shape creativity through stimuli provided by the instructor creativity (C4), synthesis and evaluation (C5-C6) $(\mathrm{HOT}=61$ percent).

\section{References}

[1] Regulation of The Minister of Education and Culture of The Republic of Indonesia. No,103, 2014. Concerning Learning in Basic Education and Middle Education.

[2] Bloom, B. (1956). Taxonomy of Educational Objectives, 18.

[3] berita/pendidikan/eduaction. [Online]. Available: republika.co. id.

[4] Sze yin Shirley Yeung," Conception of teaching higher order thinking," Perspectives of Chinese teachers in Hong Kong," Curriculum Journal. Int, 2015, vol. 26, no.4, pp. 553-578. https://doi. org/10.1080/09585176.2015.1053818

[5] P.S.Chiu, Y.H. Pu, C, C, Kao, T, T, Wu, and Y,M, Huang. Innov Educ Teach. Int., 2018, vol. 3297, no. January, pp. 1-12.

[6] Newman, F M. "Higher order thinking in teaching social studies: a rationale for the assessment of classroom thoughtfulness." Journal of Curriculum, 1990: 41-56.

[7] Kultusministerkonferenz, S. D. E. R. (2018). The Standing Conference of the Ministers of Education and Cultural Affairs of the Länder in the Federal Republic of Germany.
[8] Webb, A., and Moallem, M. (2016). Feedback and feed-forward for promoting problem-based learning in online learning environments. Malaysian Journal of Learning and Instruction, 13(2), $1-41$.

[9] Bruner, J. S. (1976). The role of tutoring in problem solving, 17(September 1974), 89-100.

[10] Palesy, D. (2017). Learning in the Absence of Direct Supervision. Person-Dependent Scaffolding, 15. https://doi.org/10. 1007/s12186-017-9176-9

[11] E.K.Juuso, An advanced teaching scheme for integrating problembased learning in control education. Open Eng, 2018, pp. 41-49. https://doi.org/10.1515/eng-2018-0006

[12] K. Safford and J. Stinton, "Barriers to blended digital distance vocational learning for non-traditional students," Br. J. Educ. Technol., 2016, vol. 47, no. 1, pp. 135-150. https://doi.org/10.1111/ bjet. 12222

[13] Borg, O’Hara, and Hutter (Online). https://go.edmodo.com/ about/

[14] Wang, Shiang-Kwe, Hui Yin Hsu, and Thomas C Re. "Professional development to enhance teachers' practices in using information and communication technologies (ICTs) as cognitive tools: Lessons learned from a design-based research study." Computers and Education, 2014: 101-115. http://dx.doi.org/10.1016/j. compedu.2014.07.006

[15] Geospatial information board of horizontal accuracy. SNI 196724-2002. http://big.go.id/assets/download/sni/SNI

[16] Geospatial information board of height accuracy. "SNI 19-69882004." http://big.go.id/assets/download/sni/SNI/SNI

[17] L. Q. Allen, “Culture and the ethnographic interview in foreign language teacher development," Foreign Lang. Ann., vol. 33, no. 1, pp. 51-57, 2000. https://doi.org/10.1111/j.1944-9720.2000. tb00889.x

[18] Hopson M H, Simms R L, Knezek G A, “Using a technologicallyenriched environment to improve higher-order thinking skills," Int. Ref. Res. J., vol. 34, no. 2, pp. 109-119, 2001. http://doi.org/ 10.1007/s11858-011-0350-5

[19] Barrows, Howard S, “Problem-based learning in Higher Education,” Int. Ref. Res. J., no. 48, pp. 3-12, 1996. http://doi.org/10. 1002/tl.37219966804

[20] Vygotsky,"Mind Society" 1978,pp. 79-91. 